\title{
P-WAVE COMPLEXITY AND FAULT ASPERITIES: THE BORREGO MOUNTAIN, CALIFORNIA, EARTHQUAKE OF 1968
}

\author{
By John E. Ebel* and Donald V. Helmberger
}

ABSTRACT

\begin{abstract}
Results from a synthetic seismogram analysis of the short-period $P$ waves from the Borrego Mountain earthquake of 9 April $1968\left(M_{L}=6.4\right)$ are used to model the strong-motion recording at El Centro. A short-period-long-period deconvolution analysis of the teleseismic $P$ waves suggested that a two-source model would fit the data much better than the single-source model presented by Burdick and Mellman (1976). Forward and inverse modeling of the data demonstrated that two sources, each of less than 2-sec duration, the second occurring $2.2 \mathrm{sec}$ after the first and both being at about 8-km depth, best fit the shortperiod waveforms. From this model, long-period synthetics were generated which were found to be quite compatible with the data. This source model was also used to synthesize the strong-motion $\mathbf{S H}$ displacement, velocity, and acceleration records from EI Centro, California. The close match of synthetics and data is used to argue that short-period waveforms contain much information about asperities which play a crucial role in the near-source strong motions from an earthquake. The Borrego Mountain event probably began with the failure of a fault asperity. The evidence for this is the several-hundred-bars stress drops of the two short-period sources and the probable location of these sources in a place where there was almost no aftershock activity or postseismic creep on the fault.
\end{abstract}

\section{INTRODUCTION}

Time domain modeling of long-period, far-field body waveforms has proven to be a very effective tool for determining source parameters of earthquakes (Helmberger and Burdick, 1979). The power behind the technique lies in the fact that synthetic seismogram methods can correctly account for free surface effects along with nearsource and near-receiver reverberations which can complicate far-field seismograms, especially those from shallow-focus events (Langston and Helmberger, 1975; Langston, 1978). While time domain studies of long-period waveforms of moderately large, shallow-focus earthquakes have become quite popular, only a few investigators have attempted to model shorter period recordings (such as WWSSN short-period records) of events of comparable size (Bache et al., 1980; Cipar, 1981; Hartzell, 1980). The reason for this is simple; long-period seismograms contain much less detailed information about the fault time history and the seismic structure along the sourceto-receiver travel path than short-period records and consequently are much easier to model. However, the short-period records are of interest precisely because they contain a more detailed look at the earthquake source process. Thus, in-depth modeling of short-period body-wave data is a useful step toward understanding seismic sources.

The Borrego Mountain, California, earthquake of 9 April $1968\left(M_{L}=6.4\right.$; see Figure 1) is particularly well-suited for a short-period body-wave study because it is an event for which there have been time domain studies of both the long-period

\footnotetext{
* Present address: Western Observatory, Department of Geology and Geophysics, Boston College, Weston, Massachusetts 02193
} 


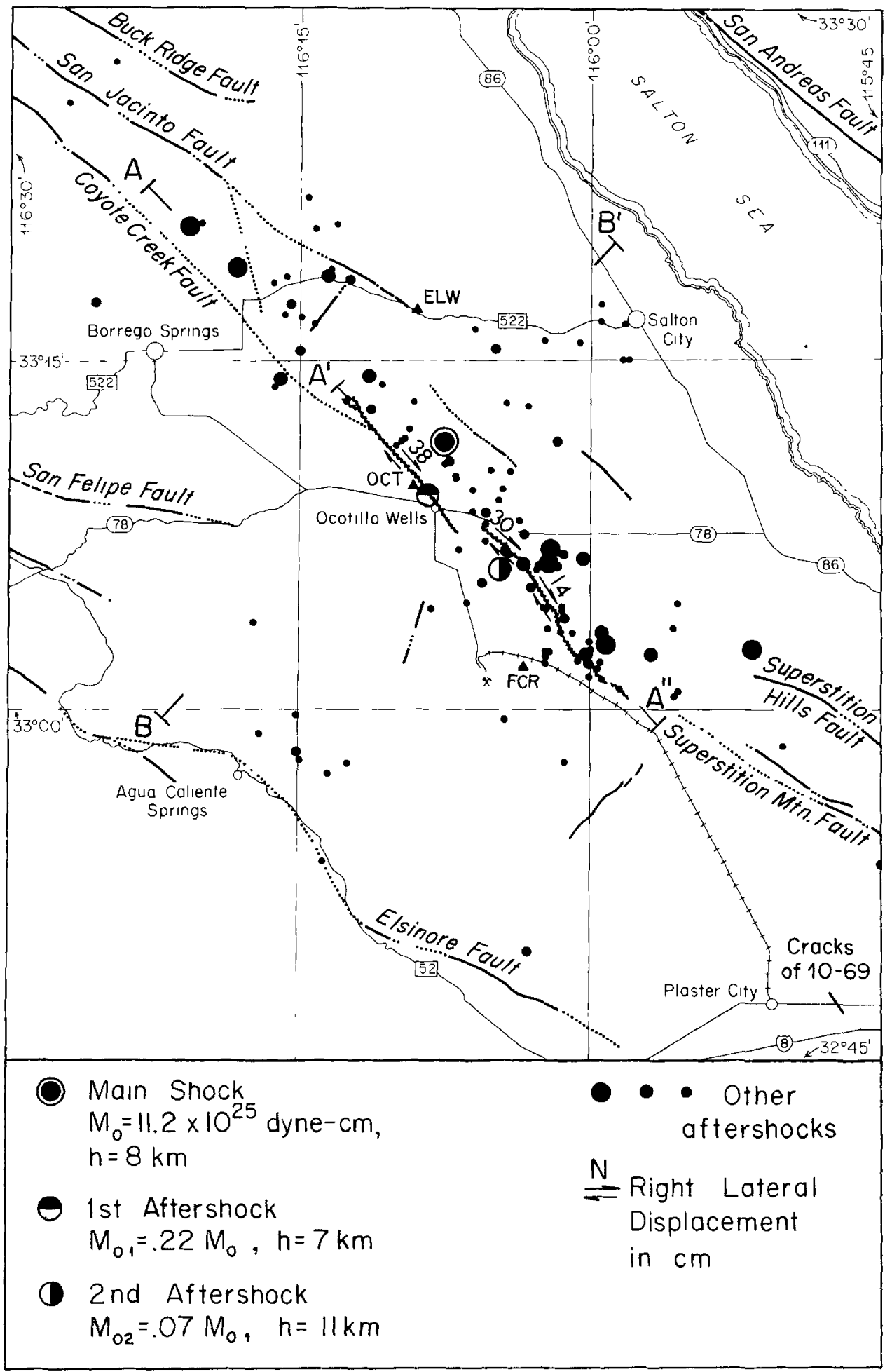

Fig. 1. Map of the focal region of the Borrego Mountain earthquake in southern Califorma from Burdick and Mellman (1976). The aftershocks from the earthquake generally lay in segment AE, while the surface faulting was confined to segment BD (BC delineates the northern fault break and CD the central and southern breaks). The location, moment $\left(M_{0}\right)$, and depth $(h)$ of each of the three sources determined by Burdick and Mellman (1976) are also shown. 
body waves (Burdick and Mellman, 1976) and the strong-motion data (Heaton. 1977; Heaton and Helmberger, 1977). In addition, the surface rupture for the event was mapped in detail (Burford, 1972; Clark, 1972), aftershock locations and focal mechanisms have been determined (Allen and Nordquist, 1972; Hamilton, 1972), and a seismic crustal structure for the source has been found (Hamilton, 1970). This wealth of information simplifies the task of modeling the short-period body waves because it provides constraints upon the types of models which can be deemed acceptable. The philosophy used in this study was to try to find a source model for

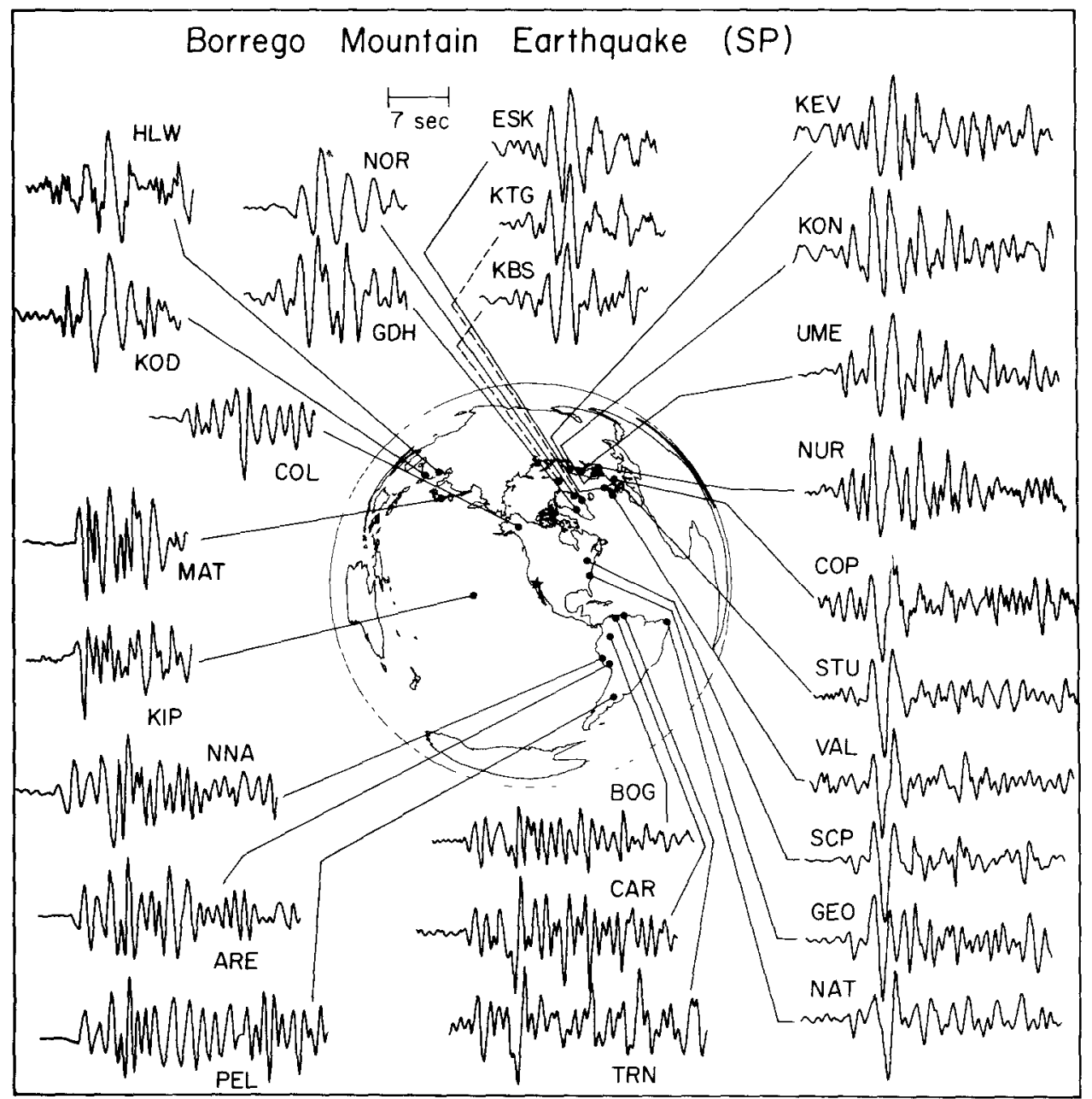

FIG. 2. Short-period $P$ waveforms recorded at $26 \mathrm{WWSSN}$ stations Note the coherence of the first several seconds of the waveforms from stations at simular azimuths The star denotes the location of the earthquake.

the teleseismic short-period data which was consistent with both the far-field longperiod and strong-motion recordings of the event from El Centro, California.

The Data Set

The short-period $P$ waves recorded at all of the stations located between $30^{\circ}$ and $90^{\circ}$ from the source are shown in Figure 2, and information on the station locations relative to the source region are given in Table 1 . At first glance, the waveforms 
appear rather complicated. The background noise on most of the records obscures the first arrival sufficiently that the initial polarities cannot be read with any certainty, and at some stations (particularly in South America), there are many seconds of high-amplitude ringing after the first arrival which may be indicative of contamination from the local receiver structures. At other stations (especially those in eastern North America and some in Europe), the seismograms are characterized by a few seconds of high-amplitude arrivals followed by a low-amplitude coda. Even with these major differences in the waveforms for stations at different directions from the epicenter, there is much coherence in the waveforms between stations at similar azimuths. In particular, the waveforms recorded at stations to the southeast of the source region (NNA, ARE, PEL, CAR, and TRN) are very similar for the first $10 \mathrm{sec}$ or so. This is likewise true of stations to the north (NOR, GDH, ESK,

TABLE 1

\begin{tabular}{|c|c|c|c|c|}
\hline \multirow{3}{*}{ Station } & \multicolumn{4}{|c|}{ Station Data } \\
\hline & \multirow{2}{*}{$\begin{array}{c}\text { Distance } \\
\left({ }^{\circ}\right)\end{array}$} & \multirow{2}{*}{$\begin{array}{l}\text { Azumuth } \\
\left({ }^{\circ}\right)\end{array}$} & \multicolumn{2}{|c|}{$\begin{array}{c}\text { Moment }\left(t^{*}=10\right) \\
\left(\times 10^{25} \text { dyne-cm) }\right.\end{array}$} \\
\hline & & & Short Period & Long Penod \\
\hline ARE & 65 & 132 & 6.67 & 6.39 \\
\hline $\mathrm{BEC}$ & 43 & 76 & & \\
\hline $\mathrm{BHP}$ & 42 & 117 & & \\
\hline $\mathrm{BOG}$ & 48 & 117 & 6.44 & 9.97 \\
\hline CAR & 50 & 105 & & \\
\hline COL & 37 & 338 & 2.47 & 9.04 \\
\hline $\mathrm{KEV}$ & 76 & 14 & 261 & 1054 \\
\hline KIP & 39 & 263 & & \\
\hline $\mathrm{KON}$ & 77 & 25 & 3.85 & \\
\hline LPB & 67 & 129 & & \\
\hline MAT & 82 & 308 & 5.66 & 7.66 \\
\hline NAT & 83 & 100 & 6.76 & 9.22 \\
\hline NNA & 59 & 133 & 3.77 & 5.75 \\
\hline NUR & 81 & 18 & 393 & 11.43 \\
\hline OGD & 32 & 64 & & \\
\hline PEL & 79 & 142 & & \\
\hline $\mathrm{SCP}$ & 31 & 65 & 502 & 6.87 \\
\hline SEO & 82 & 308 & & \\
\hline STU & 85 & 33 & 8.10 & 33.54 \\
\hline TRN & 55 & 101 & & 4.30 \\
\hline WES & 36 & 62 & & 5.43 \\
\hline
\end{tabular}

KTG, KBS, KEV, KON, UME, and NUR) and stations to the northeast (STU, VAL, SCP, GEO, and even NAT which lies somewhat southeast of the source). The similarity of the waveforms at these different stations is strong evidence that the recorded signals are dominated by information from the near-source region.

The first step taken in analyzing the data was to check the compatibility of the short- and long-period records. This was done by using the simultaneous deconvolution procedure outlined by Burdick (1977). The technique involves passing the data through a Gaussian filter, dividing instrument and Futterman attenuation operators from the long- and short-period records from a station separately, and then adding together the spectra of the two deconvolved ground motions from the different frequency bands. The information in the crossband of 0.125 to $0.5 \mathrm{~Hz}$ where the responses of the two instruments overlap is averged and the total response is 
then transformed to the time domain to get the broadband ground motion. As a check on the stability of the procedure, the responses of the different instruments are reconvolved with the attenuation operator and the deconvolved ground motion and the results are compared to the original, filtered seismograms. If there is a mismatch in the relative timing or the relative amplitudes of the two records, if the signal-to-noise ratio is poor, or if there are inaccuracies in the digitization of the records, the reconvolved traces may not match the initial, filtered traces very well. In these cases, the amplitudes and timing of the data can be redetermined and the deconvolutions recomputed.

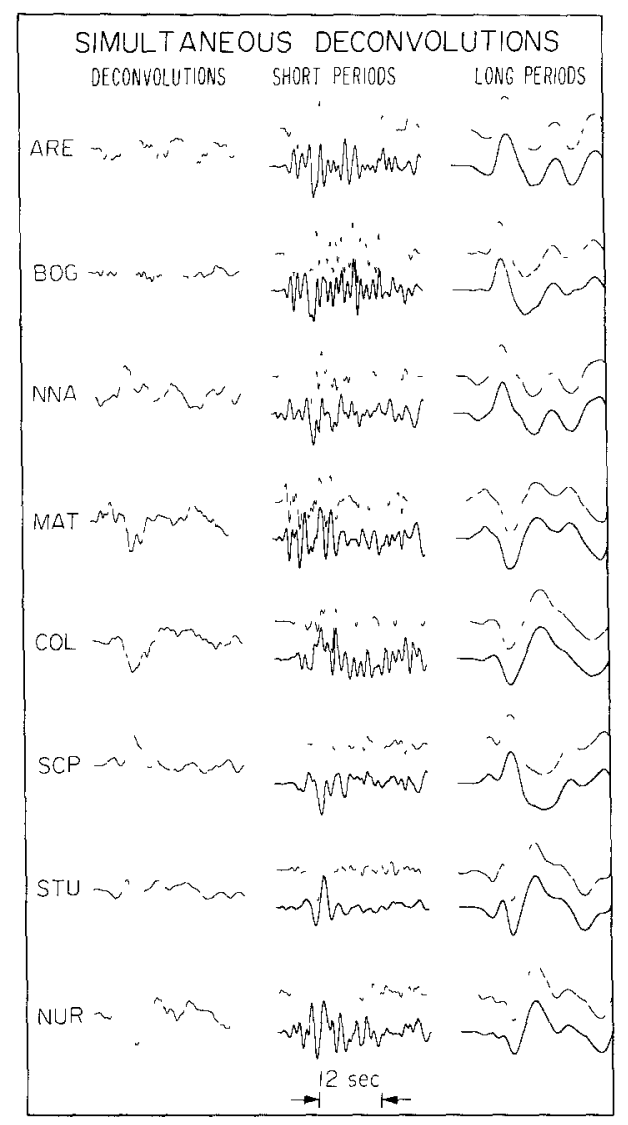

Fig. 3. Simultaneous long-period-short-penod deconvolutions of the $P$ waveforms from eight stations. For each station, a filtered version of the original data (light trace) is plotted above the reconvolved waveforms (heavy trace) The amplitudes of the waveforms are arbitrary.

Simultaneous deconvolutions for the eight stations which had the best recordings on both long- and short-period seismograms are shown in Figure 3 along with the filtered original and the reconvolved traces. A $t^{*}$ of 1.0 and a width of $1.0 \mathrm{sec}$ at the half-maximum amplitude were used in the attenuation operator and the Gaussian filter, respectively. The quality of the deconvolutions ranges from very good at ARE and MAT to very poor at STU, even after the timing and amplitudes of the original records had been checked and rechecked. The problems with the quality of the results notwithstanding, there appears to be some similarities among all of the deconvolutions. At all of the stations, the largest arrival occurs several seconds after the beginning of the $P$-wave coda. On many of the waveforms (especially those from 
which the best deconvolutions were obtained), this largest arrival is made up two distinct pulses, both of which have the same polarity. The total duration of these two pulses is between 2 and $5 \mathrm{sec}$ at most of the stations. Based upon their analysis of the long-period $P$ waves, Burdick and Mellman (1976) have identified this arrival as the $s P$ phase from the source region. The double-arrival nature of the $s P$ phase evident in the simultaneous deconvolutions probably also had its origins in the nearsource region. It was not due to receiver reverberations because it appears at different stations with undoubtedly dissimilar receiver crustal structures. This means that it must have been caused by either near-source reverberations or by two distant seismic sources which took place within a couple of seconds of each other.

A number of unusual features of the data set are obvious from the simultaneous deconvolutions. One is that the time difference between the arrival time of the $s P$ pulse and the initial $P$ phase is about 2 sec greater at MAT than at any other station with the possible exception of COL. Since source directivity affects the shape of the time functions of different phases much more than their relative arrival times, the similarity of the $s P$ phase at MAT and ARE (stations at well-separated azimuths) implies that this discrepancy cannot be attributed to source directivity. One possible explanation for this observation is that a laterally varying near-source surface structure such as a localized deep sedimentary basin northwest of the epicenter could have delayed the $s P$ phase. However, this idea is difficult to reconcile with the fact that the area on the earth's surface where $s P$ for MAT reflected was in the vicinity of Borrego Mountain where the seismic velocities are faster than the local average (Hamilton, 1970). Thus, while this $s P$ arrival time problem has no satisfactory explanation, it does adversely affect the fit of the long-period synthetic to the observation at MAT [the first swing of the Burdick and Mellman (1976) synthetic at MAT is a shorter period than that of the observation] as well as the match of the short-period synthetics and observations in this study.

A second unusual feature of the data is evident in the long- and short-period records from BOG. The $s P$ arrival on the long-period record from this station is approximately 13 times larger than the amplitude of the direct $P$ wave, while on the short-period record the $P$ and $s P$ phases are about the same size. The reconvolutions of the long- and short-period data match the initial seismograms closely which means that there was almost no mismatch of information between the waveforms digitized from the two different records. Since the focal mechanism for this event indicates that the $P$ arrival should be nodal at this station, the amplitude of the first arrival on the short-period record appears to be anomalously large. This highfrequency, high-amplitude $P$ arrival was probably due either to a rotation in the orientation of the fault plane which radiated the initial short-period energy relative to that for the long-period energy or to some sort of diffraction around the southern end of the fault which would occur if the seismic velocities to the west of the fault are higher than those to the east. Hamilton (1970) found some evidence that a velocity contrast does exist across the fault in the Borrego Mountain epicentral region although he does not quantify what this contrast might be or to what depth it may extend. If there is a velocity difference in the basement rock across the fault which affected the apparent short-period radiation pattern, it must be confined to the upper crust since the long-period $P$ and $s P$ radiation do not have anomalous relative amplitudes. On the other hand, if the amplitude discrepancy was caused by different focal mechanisms at short and long periods, it sould be evident from the modeling of the short-period records. Unfortunately, the short-period observations were not of high enough quality to resolve any short-period-long-period radiation 
pattern differences. Therefore, a strong argument for the cause of the anomalously high-amplitude short-period $P$ wave at BOG cannot be made with the data set at hand.

A third problem in the data set is that there is an unusual pattern of waveforms recorded at SCP and STU. These stations are at similar azimuths from the source region, but STU is more than twice as far away as SCP. The short-period waveforms recorded at these two stations are virtually identical, but the STU long-period record is an upside-down version of that from SCP. While a poor but acceptable deconvolution was found for SCP [one which was very similar to the good deconvolution found by Burdick and Mellman (1976) for WES, a station a few hundred kilometers north of SCP], a satisfactory deconvolution could not be found for STU. The polarities of the short-period instruments at STU and SCP were checked using first arrivals from nuclear tests and nothing unusual was found. Certainly the waveform differences between STU and SCP would not be unexpected if the shortand long-period radiation had different focal mechanisms. However, the apparent mismatch of the short- and long-period waveforms recorded at STU casts doubt upon the reliability of the data from that station. Thus, it is not possible to ascribe the cause of the differences in the seismograms from SCP and STU to effects located in the source region of the earthquake.

\section{Short-Period Modeling}

The short-period body waves from the earthquake were modeled using the timedomain synthetic seismogram method of Langston and Helmberger (1975). Synthetic seismograms for the short-period $P$ waves were generated by computing the response of a layered earth to one or more point sources and convolving it with a trapezoidal time function for each point source, a Futterman (1962) attenuation operator with a $t^{*}$ of 1.0 (unless otherwise noted) and a WWSSN short-period instrument response. The parameterization of the time functions was the same as that of Helmberger and Malone (1975) where the rise, top, and fall times of the trapezoid are designated as $\delta t_{1}, \delta t_{2}$, and $\delta t_{3}$, respectively. The time functions for all $P$ and $S$ rays which took off from a particular source were assumed to be identical, and the interaction of the incident arrivals with the near-receiver structure was not included in the models since the receiver structures for the stations used are not known.

The first step taken in analyzing the short-period $P$ records was to generate synthetics using the strike-slip source model found by Burdick and Mellman (1976) from studying the long-period body waves (Table 3). The earth response used for these synthetics was computed using the direct $P$ wave and the surface reflections $p P$ and $s P$ in the crustal model of Hamilton (1970) which is summarized in Table 2. These synthetics are compared to the observed data in Figure 4 . It is obvious that while the synthetic waveshapes do not match the observations well at all, there are several aspects of the synthetics which bear some resemblance to the data. In particular, the ratio of the amplitude of the initial arrival to the highest amplitude swing of the synthetics is approximately that of the data at many of the stations (i.e., ARE, TRN, SCP, and KIP). Also, the arrival time of this large pulse with respect to the start of the waveshape on the synthetics appears to be close to that of the data at stations where the first arrival can be isolated from the noise (ARE, SCP, TRN, and PEL are examples). The similarities between the synthetics and data suggest that the focal mechanism and source depth found by Burdick and Mellman (1976) are consistent with the short-period observations. The discrepancies 
TABLE 2

\begin{tabular}{|c|c|c|c|}
\hline \multicolumn{4}{|c|}{ Crustal Models } \\
\hline $\begin{array}{c}P \text { Velocity } \\
(\mathrm{km} / \mathrm{sec})\end{array}$ & $\begin{array}{l}S \text { Velocity } \\
(\mathrm{km} / \mathrm{sec})\end{array}$ & $\begin{array}{c}\text { Density } \\
\left(\mathrm{gm} / \mathrm{cm}^{1}\right)\end{array}$ & $\begin{array}{c}\text { Thickness } \\
(\mathrm{km})\end{array}$ \\
\hline \multicolumn{4}{|c|}{ Hamilton (1970) } \\
\hline 25 & 16 & 1.4 & 0.4 \\
\hline 5.1 & 3.0 & 2.3 & 2.5 \\
\hline 60 & 3.5 & 2.7 & 11.1 \\
\hline 7.1 & 42 & 3.2 & 11.0 \\
\hline 79 & 4.6 & 36 & - \\
\hline \multicolumn{4}{|c|}{ Mooney and McMechan (1980) } \\
\hline- & 135 & 1.7 & 1.4 \\
\hline- & 198 & 2.2 & 1.4 \\
\hline - & 2.59 & 25 & 14 \\
\hline- & 309 & 2.6 & 1.0 \\
\hline - & 3.28 & 2.65 & 1.9 \\
\hline- & 3.3 & 267 & 1.9 \\
\hline- & 3.33 & 2.69 & 1.9 \\
\hline- & 3.33 & 2.69 & 19 \\
\hline- & 336 & 2.7 & 1.85 \\
\hline- & 3.59 & 2.78 & 0.1 \\
\hline- & 381 & 2.84 & 0.95 \\
\hline- & 4.16 & 2.9 & 10.0 \\
\hline
\end{tabular}

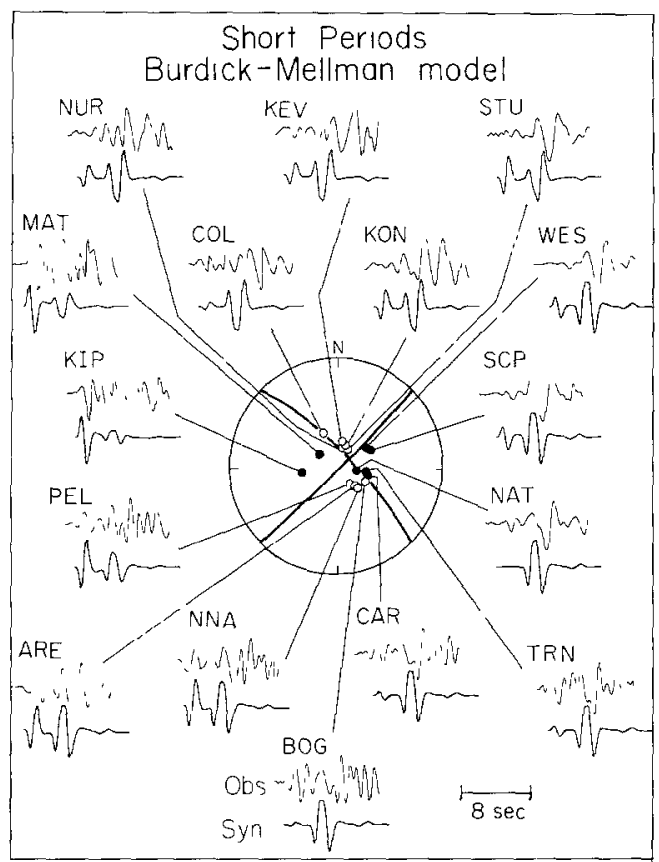

Fig. 4 Synthetic short-period $P$ waveforms computed from the Burdick and Mellman (1976) strikeslip source model compared to the data. The closed curcles in the focal mechanism represent compressional arrivals, while the open circles are dilatational arrivals. The amplitudes of the waveforms in this and all of the following figures are arbitrary unless otherwise noted

between the synthetics and data, in particular the fact that the synthetics lack some of the high-frequency nature of the observations, is evidence that the source-time function of Burdick and Mellman (1976) is not entirely appropriate at shorter periods. 
On all of the synthetics from the Burdick-Mellman model (Figure 3), the large arrival which occurs several seconds into the waveforms is the $s P$ phase, and from the simultaneous deconvolution analysis, it was evident that there were two separate pulses which contributed to making up the $s P$ phase. This suggested that more than one source was needed to model the short-period records. Several different sets of synthetics computed with two point sources were found to give a fit which was much better than that from the single point-source model of Burdick and Mellman (1976). With the two-source models, the fit of the synthetic $P$ arrival to that of the data at most stations was still not good, but this is not surprising since the signal-to-noise ratio is generally poor for this part of the record. However, the similarity of the synthetic $s P$ phase to that of the data was improved for most of the records. The synthetics generally fit the data quite well at stations in Europe (with the exception of STU which was found to be a questionable station in the deconvolution analysis) and eastern North America, but for the South America stations, they lacked some of the high-frequency characteristics of the data.

\section{INVERSION MODELS}

An effort was made to improve the fit of the synthetics to the short-period data and to explore the uniqueness of the source models by employing the waveform inversion technique used by Burdick and Mellman (1976) to model the long-period body-wave records. The procedure involves computing changes in the source model based upon cross-correlations of the synthetic and observed waveforms at each station. In practice, the inversion program was allowed to iterate a number of times on the source model until it could no longer improve the cross-correlations of the synthetic and observed waveforms at each station. In practice, the inversion program was allowed to iterate a number of times on the source model until it could no longer improve the cross-correlations. For the Borrego Mountain data set, the only rays used in the inversion process were the same three as those used in the initial forward modeling. The only short-period waveforms that were used were those where the signal-to-background-noise ratio was large and where it was felt that there was the least contamination by receiver reverberations. Since each station was given a weighting, stations with waveforms of questionable quality could be deemphasized in the inversion process so that they did not contribute very much to the final model which the program found.

The parameters which were allowed to vary in the inversion runs were the three parts of the trapezoidal time function, the focal mechanism and depth of each of the two sources, and the time lag of the second source with respect to the first. The program was first used on a data set of six short-period records (STU, ARE, BOG, KON, ARE, and SCP) using the starting model listed in Table 3. The final model from this inversion is given as the short-period inversion model in Table 3 and synthetics for all of the short-period records are shown in Figure 5. A comparison of the cross-correlation values between the final and the starting models reveals that the inversion procedure improved the fit by about 10 per cent at each station. The inversion made only minor alterations in the parameters for the first source, but it made rather substantial changes in the focal mechanism and time function of the second source. The result of these changes was to make the second source have a focal mechanism with the approximate strike of $193^{\circ}$ but with a time function very different from those of the first source. The inversion program left both sources at depths of about $8 \mathrm{~km}$. Long-period synthetics were also computed using this model 
and they are shown in Figure 6. In general, they fit the observations reasonably well.

The inversion process was also performed on a data set which included all the seismograms used in the short-period inversion plus records from 17 long-period

TABLE 3

Source PARAMETERs

\begin{tabular}{|c|c|c|c|c|c|c|c|c|c|}
\hline & \multicolumn{3}{|c|}{ Mechanısm } & \multicolumn{4}{|c|}{$\begin{array}{c}\text { Time } \\
\text { Function }\end{array}$} & \multirow{2}{*}{$\begin{array}{c}\text { Depth } \\
(\mathrm{km})\end{array}$} & \multirow{2}{*}{$\begin{array}{l}\text { Delay } \\
\text { Time } \\
\text { (sec) }\end{array}$} \\
\hline & Strike & Dip & Rake & $\delta t_{5}$ & $\begin{array}{c}\delta t_{2} \\
\text { (sec) }\end{array}$ & $8 t_{3}$ & Amp & & \\
\hline Burdick-Mellman Model & -45 & 81 & 178 & 0.36 & 0.0 & 0.45 & 1.0 & 8.0 & - \\
\hline \multicolumn{10}{|l|}{ Startıng Model } \\
\hline Source 1 & -45 & 80 & 180 & 0.3 & 1.0 & 03 & 1.0 & 80 & 0.0 \\
\hline Source 2 & -30 & 80 & 180 & 03 & 1.0 & 0.3 & 1.0 & 80 & 20 \\
\hline \multicolumn{10}{|c|}{ Short-Period Inversion Model } \\
\hline Source 1 & -43 & 78 & 178 & 0.89 & 0.82 & 076 & 1.0 & 8.2 & 0.0 \\
\hline Source 2 & -30 & 63 & 193 & 0.31 & 0.64 & 073 & 0.34 & 9.0 & 2.3 \\
\hline \multicolumn{10}{|c|}{ Simultaneous Inversion Model } \\
\hline Source 1 & -43 & 78 & 178 & 0.54 & 0.89 & 0.75 & 1.0 & 7.3 & 0.0 \\
\hline Source 2 & -38 & 68 & 197 & 0.05 & 005 & 1.2 & 0.35 & 8.4 & 2.2 \\
\hline
\end{tabular}

For all models, the second source was located $5.4 \mathrm{~km}$ southeast of the furst.

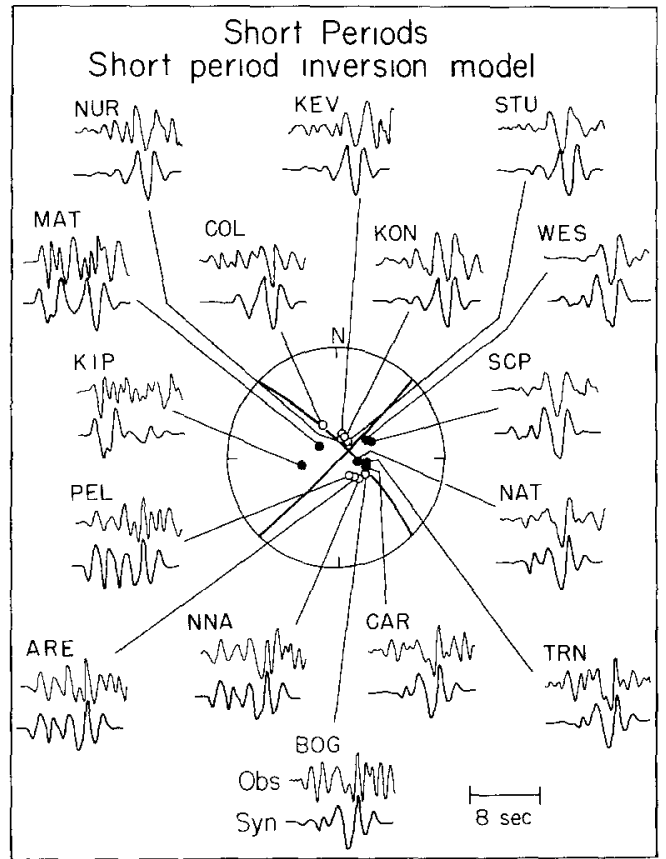

Fig 5 Short-period synthetics from the short-period inversion model compared to the data

stations used by Burdick and Mellman (1976). Once again, focal mechanisms, depths, time functions, and relative time of the events were freed in the inversion program, and the starting model was the same as that used for the inversion of the shortperiod data set. The source models which resulted from the inversion of this data 
set are given as the simultaneous inversion model in Table 3 and the synthetics are shown in Figures 7 and 8 . The cross-correlations were once again improved by about 10 per cent at each station. Here also the inversion program changed the parameters

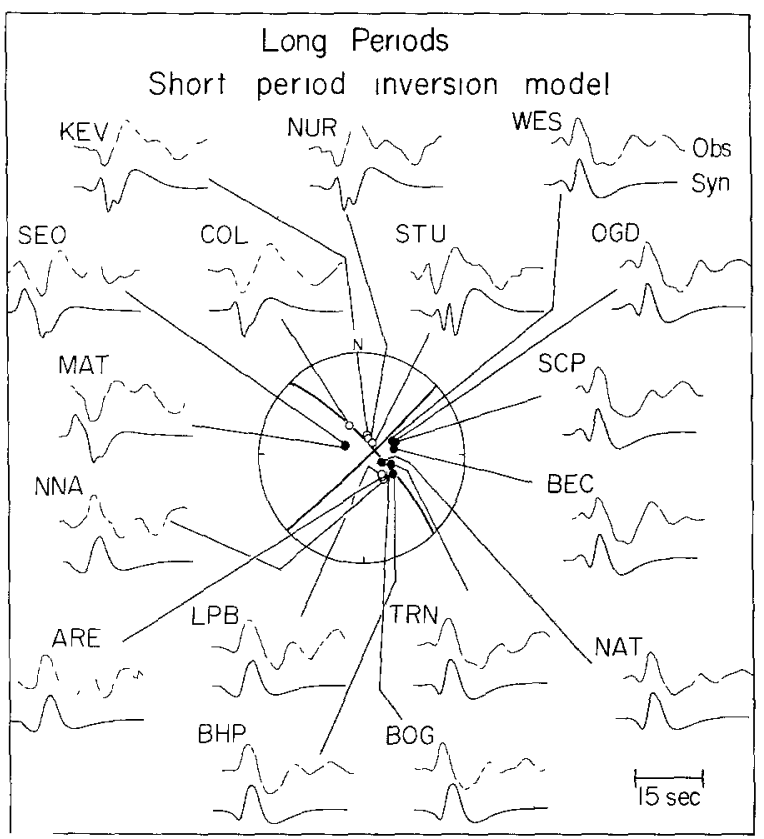

FIG. 6 Long-period synthetics from the short-period inversion model compared to the data.

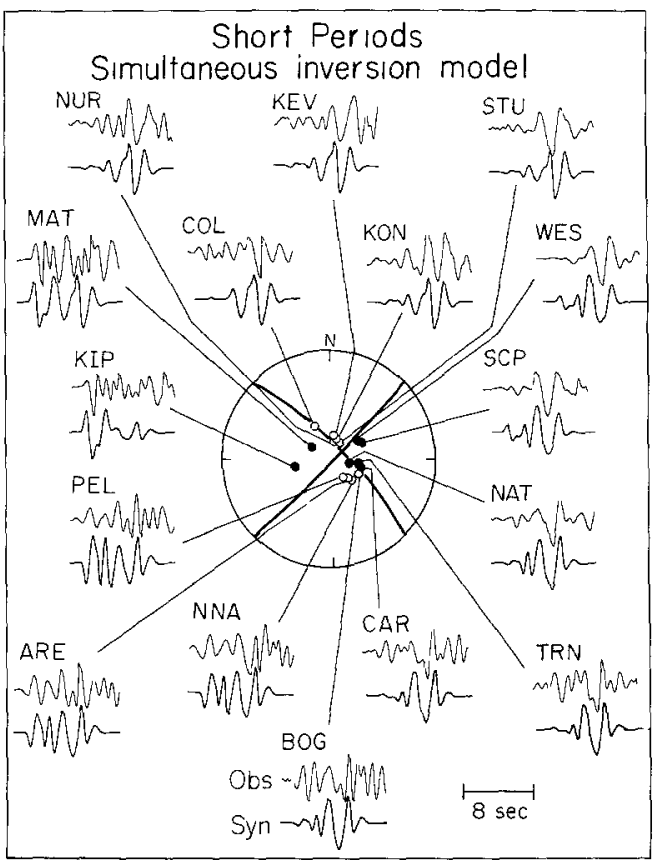

FIG 7 Short-period synthetics from the simultaneous inversion model compared to the data.

of the second source much more than those of the first and the final models for the two sources are similar to those found from the short-period inversion except for the shape of the time function and the strike of the second source. This simultaneous 
inversion demonstrates that the two-source model which is necessary to fit the short-period data is also quite compatible with the long-period waveforms. The difference in the time functions of the second source found from inverting the two different data sets also gives a good feeling for the resolution of the modeling process. From comparing the models in Table 3, it appears that the methods used here are much more capable of determining the source parameters for the larger first source than for the smaller second source. Nevertheless, many parameters of the two sources are well determined from the modeling. The first source was at about $8-\mathrm{km}$ depth, had a duration of about $2.2 \mathrm{sec}$, and had strike, dip, and rake of $-43^{\circ}, 78^{\circ}$, and $178^{\circ}$, respectively. The second source took place about 2.2 sec after the first, was only about a third of the amplitude of the first, was located at a depth of about $8.5 \mathrm{~km}$, and had a strike, dip, and rake of $-38^{\circ}, 68^{\circ}$, and $194^{\circ}$.

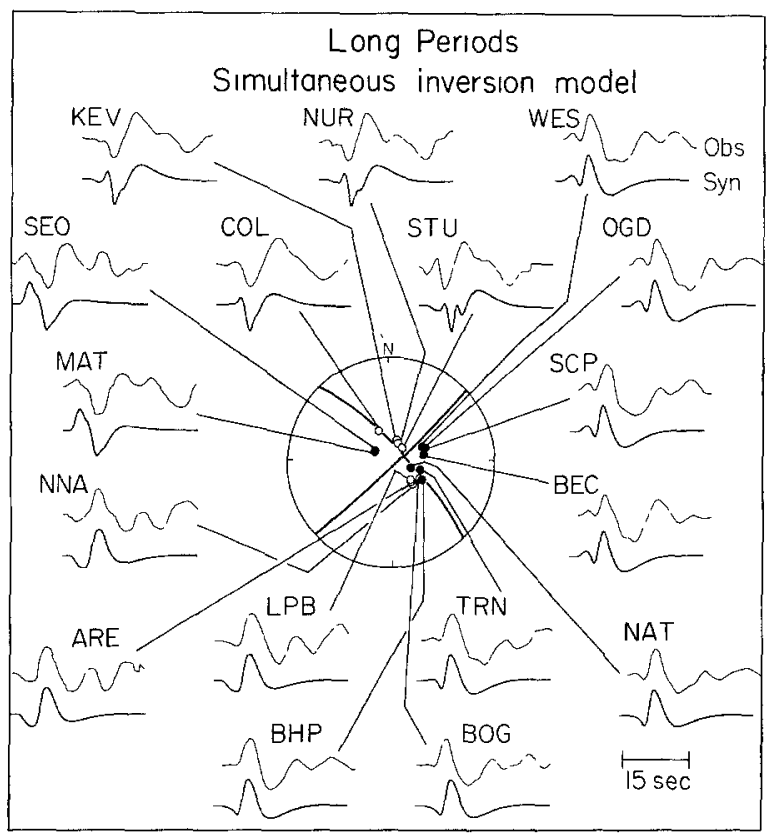

FrG 8. Long-period synthetics from the simultaneous inversion model compared to the data.

None of the inversion runs on either of the two data sets was able to resolve the simultaneous waveform problems found at BOG and STU, nor were they able to find a model which satisfactorily fit the waveforms at MAT. In fact, there are noticeable differences between all of the short-period synthetics and data in Figures 5 and 7. While this is not surprising because of the low signal-to-noise ratio for the data set, it does make it difficult to judge how well the synthetics model the data. A better feeling for the quality of the fits can be obtained by considering how well the deconvolved waveforms can be matched. Synthetics which have been computed without either instrument response or attenuation are compared in Figure 9 to the results of the simultaneous deconvolution analysis presented in Figure 3 . The model used for the synthetics in Figure 9 was that found from the simultaneous inversion modeling. In general, the fit is very good at ARE and NNA, and, except for a somewhat strong synthetic $p P$ phase at BOG and SCP, the synthetics match the data at these stations also. The deconvolved synthetic at MAT was found to match 
the data best if the synthetic $s P$ phase was aligned with the arrival which was identified as the $s P$ phase in the data, and so this is the way that the comparison at MAT is plotted in Figure 9. Because of this, the first arrivals of the synthetic and observation do not coincide. The fits at COL, STU, and NUR are poor, but this is not surprising since good deconvolutions at STU and COL could not be obtained and the signal-to-noise ratio was very low for the data from NUR. The deconvolution synthetics show that, while the theoretical time functions lack some of the details of the data (especially the long-period information), the source model is a reasonable interpretation of the data.

The inversion modeling was all done assuming that the short-period records could be closely modeled using only the direct $P$ wave and the $P$ and $S V$ free-surface reflections. This assumption was justified by comparing synthetics computed from these three rays with those calculated from a full crustal response. The similarity of the synthetics computed from these two methods is demonstrated in Figure 10. The

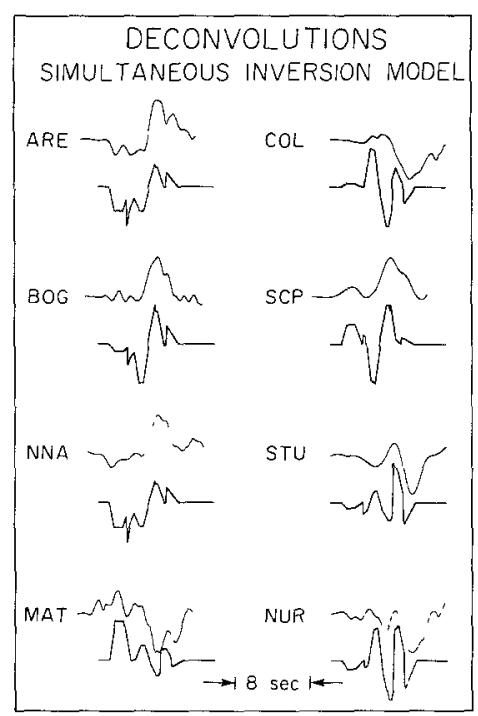

Fig. 9. Comparison of synthetics computed from the simultaneous inversion model without instrument or attenuation and the deconvolved observations. The synthetic at MAT was time shifted by about 2 sec so the $s P$ phases of the datum and synthetic are matched. The alignment of the synthetic waveforms at COL, STU, and NUR with the data is somewhat arbitrary since the traces have very different shapes.

source parameters used for both synthetics were those found from the simultaneous inversion modeling, and the full crustal response synthetics were calculated using Fuchs' (1966) modification of the Thomsen-Haskell layer matrix method with the near-source crustal structure being that reported by Hamilton (1970). The two sets of synthetics are very similar for NAT, KON, and SCP. For ARE, the amplitudes of the peaks and troughs of the two synthetic waveforms are somewhat different while the phases of the two waveforms are quite similar and, in fact, match the phase of the observation very closely. From these examples, it is evident that the waveforms contain much more information about the earthquake source time history than about the near-source structure and that the direct $P$ wave and the free-surface reflections are by far the most important phases for determining the shapes of the synthetic waveforms.

Seismic moments for the earthquake were computed from the simultaneous 
inversion model by averaging the moments calculated from several of the stations. Values for the short- and long-period moments computed from the simultaneous inversion model for $t^{*}=1.0$ are given in Table 1 for those stations where moments were determined. The average moments for all the short-period records are $5.0 \times$ $10^{25}$ dyne-cm for a $t^{*}$ of 1.0 and $7.7 \times 10^{25}$ dyne-cm for $t^{*}$ of 1.3 . The corresponding average moments for the long-period data (excluding STU where the value was found to be clearly inconsistent with the rest of the data) are $7.6 \times 10^{25}$ dyne-cm and $8.8 \times 10^{25}$ dyne-cm, respectively. The difference between the short- and long-period moments must be due to the existence of a very long-period part of the time function which was not found during the modeling process. Since the fault length determined from surface cracking and aftershock locations (Clark, 1972) is much larger than that which was estimated from the long-period body-wave modeling (Burdick and Mellman, 1976), the existence of a long-period part of the source time history is quite reasonable.

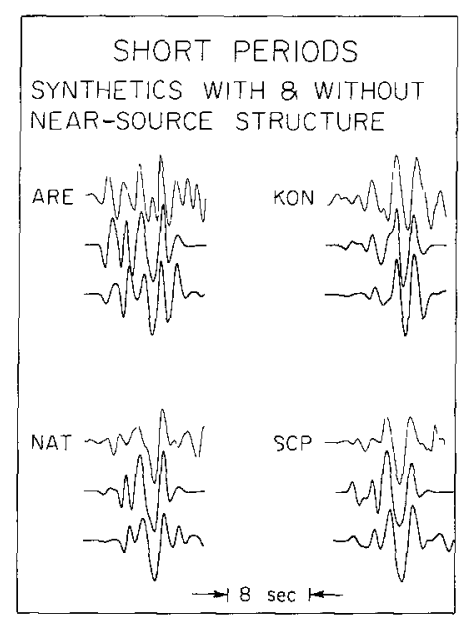

FIG. 10. Comparison of the data (top trace, light line) with synthetics computed from just $P, p P$, and $s P$ (middle trace, heavy line) and with synthetics computed from the full response of the near-source crustal structure (bottom trace; heavy line) at ARE, KON, NAT, and SCP.

\section{Strong-Motion Modeling}

Data from the earthquake was also recorded on a good set of acceleration and Carder displacement seismograms at El Centro, California, located about $60 \mathrm{~km}$ to the south-southeast of the epicenter. The highest acceleration, which was measured on the north-south component of the accelerometer, was $128 \mathrm{~cm} / \mathrm{sec}^{2}$, while the maxima on the vertical and east-west components were 30 and $56 \mathrm{~cm} / \mathrm{sec}^{2}$, respectively. The accelerometer triggered sometime during the arrival of the $P$-wave train so it did not record the initial arrival of energy. However, the $S$ wave and some surface waves were well-recorded by the instruments which remained triggered for about $60 \mathrm{sec}$.

The acceleration records have been integrated into velocity and displacement waveforms, and the horizontal displacement traces were found to match the Carder displacement records quite well, as discussed by Heaton (1977). The north-south record, which is shown in Figure 11, is of particular interest because it represents primarily $S H$ motion. Heaton and Helmberger (1977) have done extensive modeling of the $S H$-displacement record. They determined that the long-period oscillations 
which characterized most of the later part of the displacement record were due to $S H$ rays trapped in a near-surface crustal layer and that they could isolate a sourcetime function by modeling the initial part of the $S H$ wave train. The time function from their best model was actually the sum of three different time functions-two triangles of 1-sec duration each located at a depth of $8 \mathrm{~km}$ and occurring $2 \mathrm{sec}$ apart, and a third low amplitude, long-period time function put at $4-\mathrm{km}$ depth and beginning at the same time as the first source. The shape of the time function of Heaton and Helmberger (1977) as it would appear to teleseismic stations is shown in Figure 12 along with that of Burdick and Mellman (1976) and the time history determined from the simultaneous inversion as listed in Table 3. It can be seen that the Heaton and Helmberger (1977) time function and that determined from this study are quite similar, and that the Burdick and Mellman (1976) time function is a smoothed version of the other two.

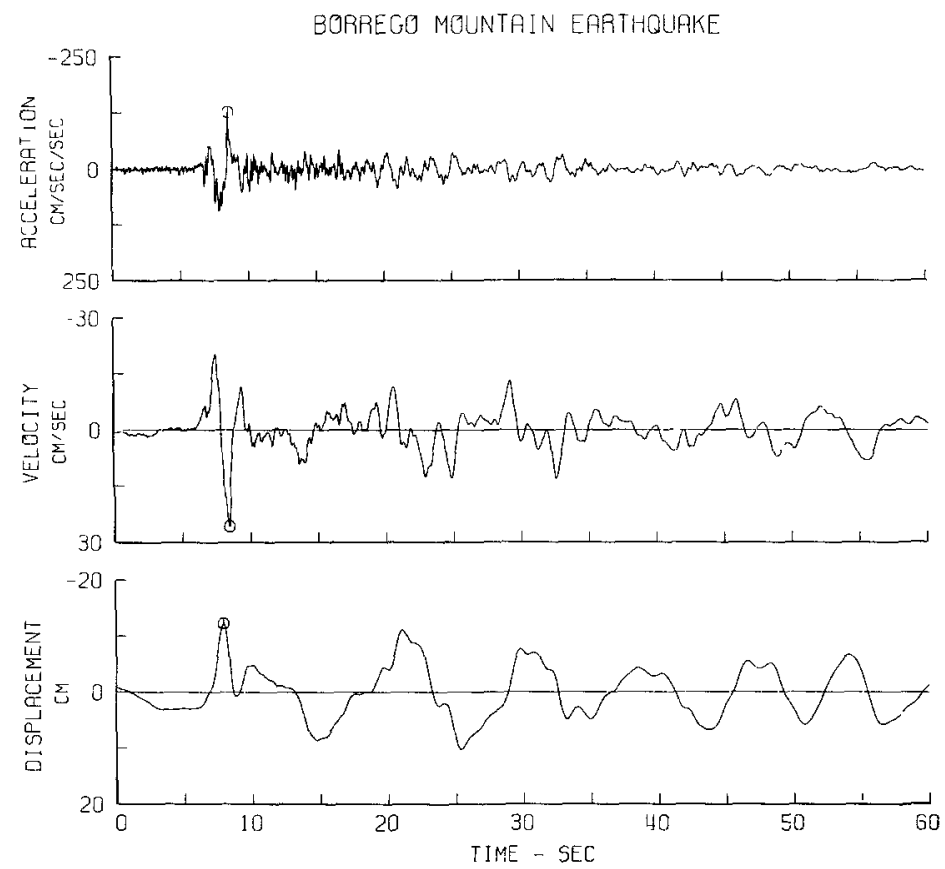

Fig 11 Corrected acceleration, velocity, and displacement records from the north-south component of the strong ground motion recorded at El Centro, California (from U.S. Coast and Geodetic Survey et $a l, 1968)$.

The success in modeling both the teleseismic short-period $P$ waves and the strongmotion $S H$ ground displacements at El Centro was an inducement to try to understand the north-south velocity and acceleration records at El Centro. This is not an easy thing to do since the synthetic velocity and acceleration traces are calculated from derivatives of the synthetic displacement record, and small changes in the shape of the displacement record have large effects on the waveshapes and amplitudes of the synthetic velocity and acceleration. On the other hand, the modeling is simplified somewhat since, by far, the highest amplitude velocity and acceleration arrival is that of the $S$ wave (Heaton and Helmberger, 1977) which is found between about 7 and $10 \mathrm{sec}$ after the beginning of the record (Figure 11). Attention was restricted to understanding this part of these two records. 
Initial modeling of the $S$ wave on the velocity and acceleration records revealed that the waveform is not made up of a single direct arrival from the source as assumed by Heaton and Helmberger (1977) but that there are some important crustal complications involved in it. The differences can be seen in the step function responses shown in Figure 13. The response in Figure 13a is made up of a simple direct arrival plus later reverberations in a near-surface sedimentary basin. The response in Figure 13b shows the response from a source located in a crust with a

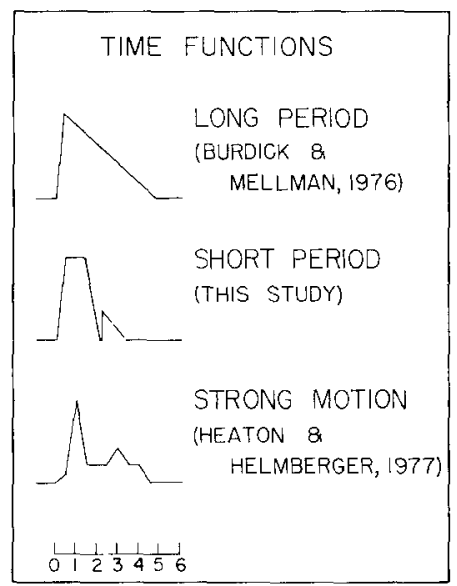

FIG. 12. Comparison of the time functions for the Borrego Mountain earthquake determined from the long-period body waves (top), short-period body waves (center), and strong motion data (bottom). The time scale at the bottom is in seconds.

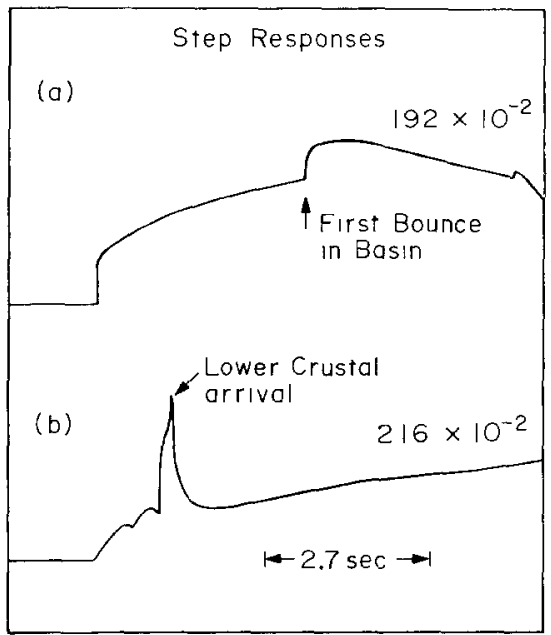

Fig. 13. Step function responses for initial $S H$ arrivals from (a) the study of Heaton and Helmberger (1977) and (b) the crustal model of Mooney and McMechan (1980) as computed in this study. Peak amplitudes from a unit point source are given in each case.

modification of the crustal structure proposed by Mooney and McMechan (1980) listed in Table 2 (the basin bounces are not included in this response). The latter response, in which only the most significant rays are included, has a strong reflection from the lower crust which occurs a little over a second after the initial arrival. This response was the one used in the calculation of the synthetics.

From the initial modeling, it was also found that the large initial source-time 
function needed to be symmetric in shape. The best trapezoidal time function was found to be one with durations of the legs and top of 0.8 and $0.2 \mathrm{sec}$, respectively. It was necessary to filter this time function in order to make it smoothly differentiable. A symmetric time-domain triangle was used as this filter. It was discovered that the synthetics were quite sensitive to the width of this smoothing filter. Synthetic displacement, velocity, and acceleration records for the trapezoidal source smoothed with triangles which have legs of duration $(\tau)$ 0.2, 0.3, and $0.4 \mathrm{sec}$ are shown in Figure 14. The general shape of the synthetics fit the observations fairly well, but the frequency content and amplitude of the velocity and especially the acceleration

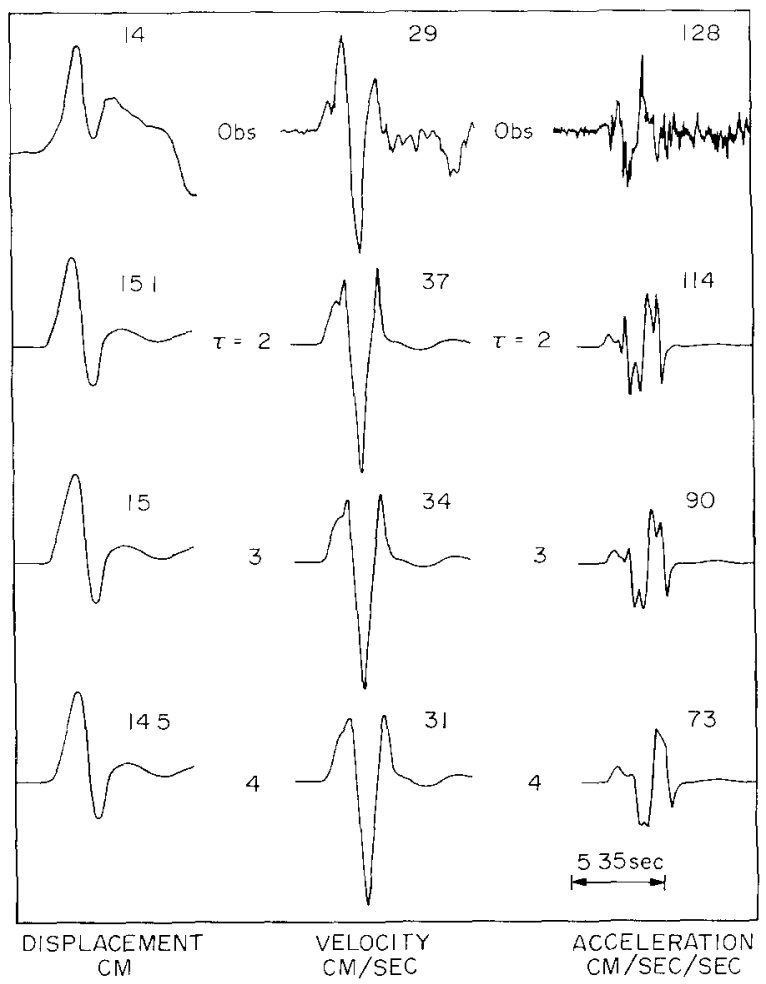

FIG. 14. Synthetic displacement, velocity, and acceleration records (lower three lines) for the first source are compared to the data (top line) from the north-south El Centro strong ground motion record. Peak amplitudes for each trace are shown with the units at the bottom of each column. The duration of the legs of the triangle filter $\tau$ are also given.

records are strongly affected by the choice of the filter duration. Thus, a time function which best fits the data could be found by varying the width of this smoothing filter.

The second source, which had been inferred by both the teleseismic short-period $P$ wave and the strong-motion displacement modeling, was added to the model and synthetics were again computed in an effort to understand how it may affect the waveforms. This source was approximated by using the analytic time function of Haskell (1967). This source time history, which is shown together with its displacement, velocity, and acceleration time functions in Figure 15, has been used in the description of the source-time functions of large explosions. The reason for using it here was two-fold: the source could be smoothly differentiated to find accelerations 
and the accelerations from the source are basically a pulse with a sharp rise followed by a long tail. The latter was felt to be important because the highest peak on the acceleration record has this one-sided nature. The source is parameterized by one independent constant $k$ which was varied until the pulse had roughly a 1.2 -sec duration. Synthetic accelerograms with two sources where the second source has $k$ $=5$ and $k=7$ ( $\tau=0.3$ for both) and a moment of $6.4 \times 10^{25}$ dyne-cm are shown in Figure 16 along with plots of the displacement time histories of the second sources. The time separation of the two sources necessary to best fit the data was 1.6 sec. While this is less than the $2.2 \mathrm{sec}$ found from the teleseismic modeling, the peak of the displacement time function with $k=5$ occurs about $2.2 \mathrm{sec}$ after the first source. Thus, if the Haskell (1967) time function is thought of as a smoothed version of the teleseismic short-period triangular source, the discrepancy in the timing of the two

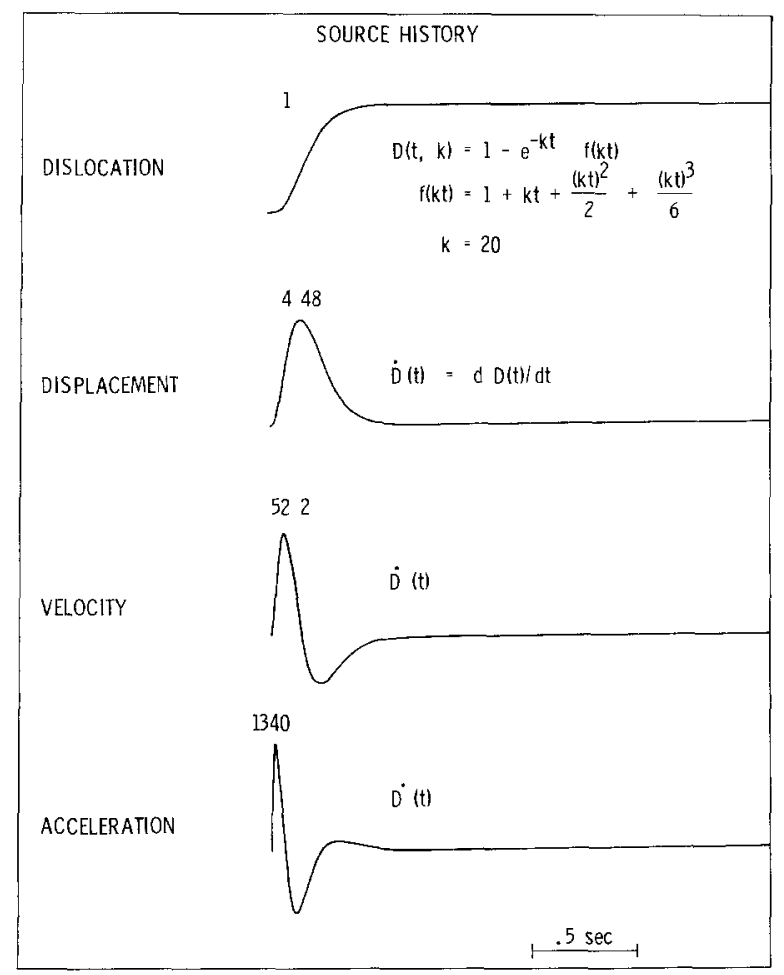

Fig. 15. Description of the Haskell (1967) source The peak amplitude of each waveform is given above the trace.

sources found at El Centro and in the teleseismic short-period body waves is unimportant. It is evident from Figure 16 that the effect of the second source is to add high-frequency information to the acceleration record synthesized with just the first source. The velocity and displacement synthetics are almost totally unaffected by the addition of the second source.

One of the most puzzling features of the El Centro records is that the $S H$ pulse shows up much more strongly on the north-south than on the east-west component whereas both components should have similar amplitudes. This could be due to the arrival not following the shortest path from source to receiver or from a rotation of the focal mechanism relative to that found in the modeling process. The former suggestion is unlikely given what is known about the crustal structure of the Imperial 
Valley (Mooney and McMechan, 1980), but the latter requires an $18^{\circ}$ change in the fault strike relative to that given in Table 3 for the inversion models (to a more eastwest striking fault). To test how this latter suggestion would affect the far-field waveforms, synthetic long- and short-period waveforms were computed with the simultaneous inversion model where the source strikes were changed to $-61^{\circ}$ and $-54^{\circ}$. These synthetics are shown in Figure 17. The short-period records do not fit quite as well over all as with the best-fitting models described earlier, but on the other hand, the match is not bad. Some stations like NAT and BOG appear improved by the rotation in fault strike (Figure 17a). The long-period fits are noticeably different at many stations, and generally for the worse (Figure 17b). On the basis of the short-period data alone, one could conclude that the strike of the short-period part of the seismic break was rotated by $18^{\circ}$ relative to the long-period

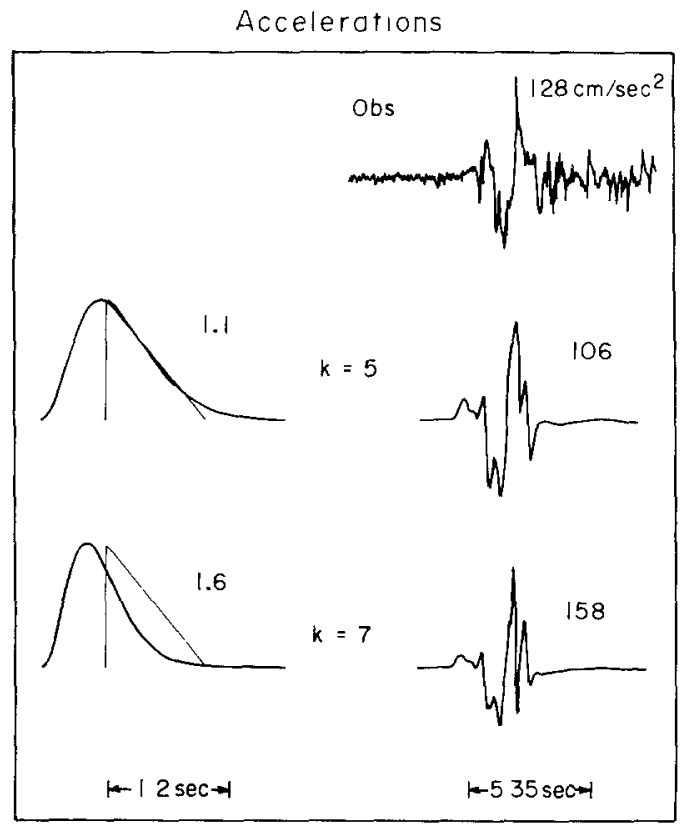

FIG. 16 Synthetic accelerations (lower traces) computed from the two-source model are compared to the observed north-south acceleration record from El Centro (top trace). Also plotted on the left are the time functions for the second source computed from the Haskell (1967) formulation and the shape of the second source (the triangles) found from the simultaneous inversion. The triangles have been shifted $0.6 \mathrm{sec}$ relative to the beginning of the Haskell (1967) source. Peak amplitudes of the accelerograms in $\mathrm{cm} / \mathrm{sec}^{2}$ are given next to the traces, as are the peak amplitudes (m arbitrary units) of the Haskell (1967) time functions.

level coupled with the long-period data, although one must regard this hypothesis with uncertainty.

\section{Discussion}

The results of the strong-motion modeling combined with the analysis of the short-period data strongly indicate that much energy from the earthquake was radiated in two pulses of about $3 \mathrm{sec}$ total duration. The duration of these pulses is approximately the same at all azimuths for which there is good data, so there is little evidence for directivity in the source. If the rupture is assumed to have initiated at a single point on the fault and then propagated circularly away with a subsonic rupture velocity, the area which radiated these pulses must have been small compared to the fault size inferred from the aftershocks and surface breakage. 
From the source parameters of the earthquake given in Table 3 and using the assumptions just made, some of the details of the faulting process can be quantified. Fault areas and stress drops were computed from the formulations of Ebel $e t$ al. (1978) and Kanamori and Anderson (1975), respectively, and are given in Table 4. The faults areas for the short- and long-period sources are assumed to be circular and that for the entire main shock was approximated from the aftershock distribution (see Figure 18). It is evident from Table 4 that the two sources found from short-period body-wave analysis broke only about 15 per cent of the total fault plane. These sources also had very large seismic moments, and it is the combination of these two parameters that gives then the high stress drops. A stress drop of 96
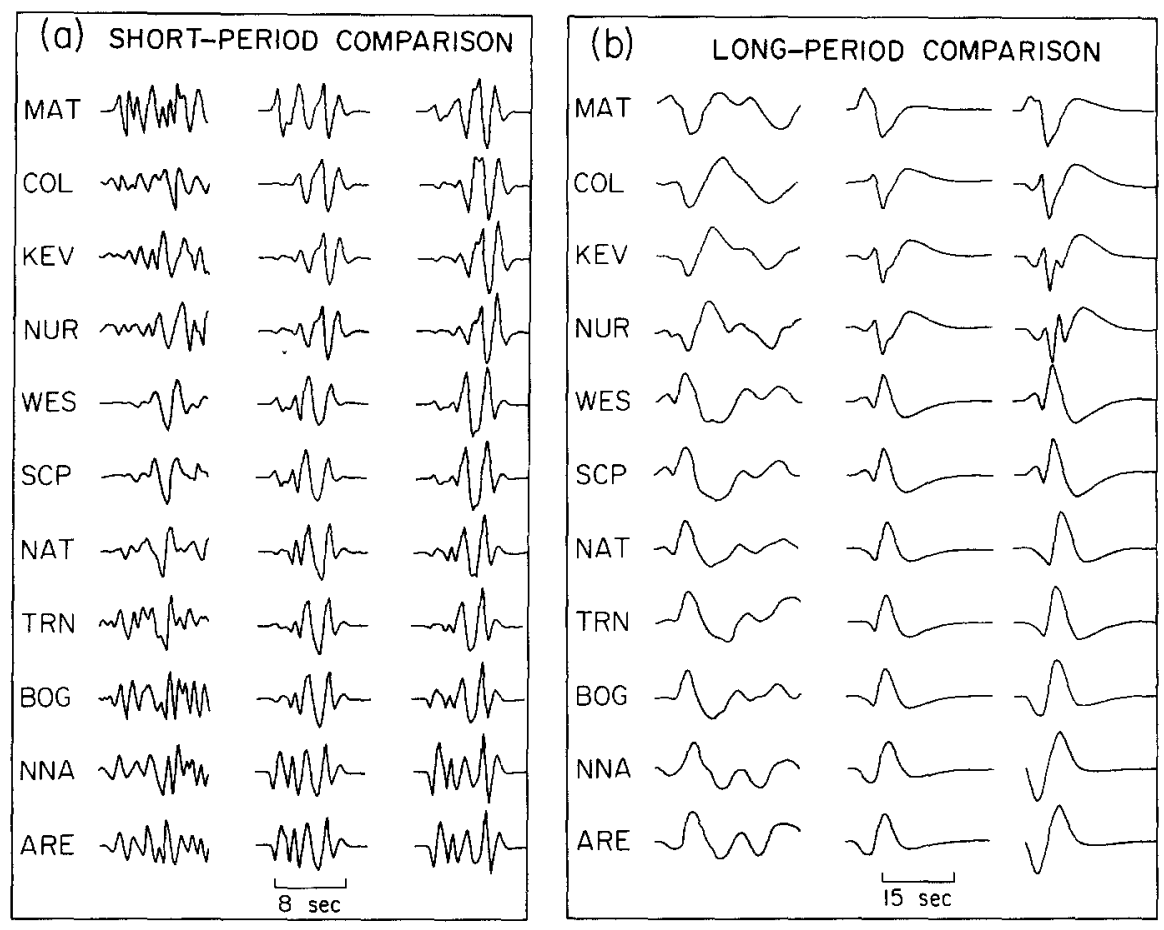

Fig. 17. (a) Short-period data (left column), sumultaneous inversion model synthetics (center col$u m n$ ), and synthetics of the sumultaneous inversion model with the fault strikes rotated by $18^{\circ}$ (right column). Representative stations at different azimuths are shown. (b) Long-period data (left column), simultaneous inversion model synthetics (center column), and synthetics of the simultaneous inversion model with the fault strikes rotated by $18^{\circ}$ (right column).

bars was determined by Burdick and Mellman (1976) from their study of the longperiod body waves, and a still lower stress-drop value of 20 bars for the event was computed from the total fault area given in Table 4 and the surface-wave moment of $3 \times 10^{26}$ dyne-cm (Burdick, 1977). These stress-drop estimates show that while the rupture initiated with two very high stress-drop events, the total rupture had a much lower average stress drop.

The location of the region which radiated the two high-amplitude pulses may have been the northern end of the fault zone where the epicenter of the event as well as that of the immediate foreshock were located (Allen and Nordquist, 1972) and where the largest surface displacements were measured (Clark, 1972; Figure 
19). The reason for this is that the first arrivals on the teleseismic records as well as the initial $S H$ pulse at El Centro are dominated by these strong arrivals. As the initial motions at the Caltech network stations put the hypocenter near the northern end of the fault (Figure 1), the first arrivals at the teleseismic stations probably also came from this source region. The distribution of aftershocks projected on the fault determined by Hamilton (1972) which is reproduced in Figure 17 has an interesting feature. At the northern end of the fault trace there is a gap of about $6 \mathrm{~km}$ where

TABLE 4

Fault Areas and Stress Drops

\begin{tabular}{lcccc}
\multicolumn{1}{c}{ Event } & $\begin{array}{c}\text { Characteristic } \\
\text { Fault } \\
\text { Dimensions } \\
(\mathrm{km})\end{array}$ & $\begin{array}{c}\text { Fault } \\
\text { Area } \\
\left(\mathrm{km}^{3}\right)\end{array}$ & $\begin{array}{c}\text { Selsmie Moment* } \\
\text { (dyne-cm) }\end{array}$ & $\begin{array}{c}\text { Stress Drop } \\
(\mathrm{bars})\end{array}$ \\
Source 1 & 7.7 (diameter) & 47 & $64 \times 10^{25} \mathrm{~b}$ & $0.9 \times 10^{25} \mathrm{~b}$ \\
Source 2 & 4.0 (diameter) & 13 & $30 \times 10^{26} \mathrm{~s}$ \\
Total Fault & $12 \times 30$ & 360 & 366 \\
\hline
\end{tabular}

${ }^{*}$ b, body wave; s, surface wave.

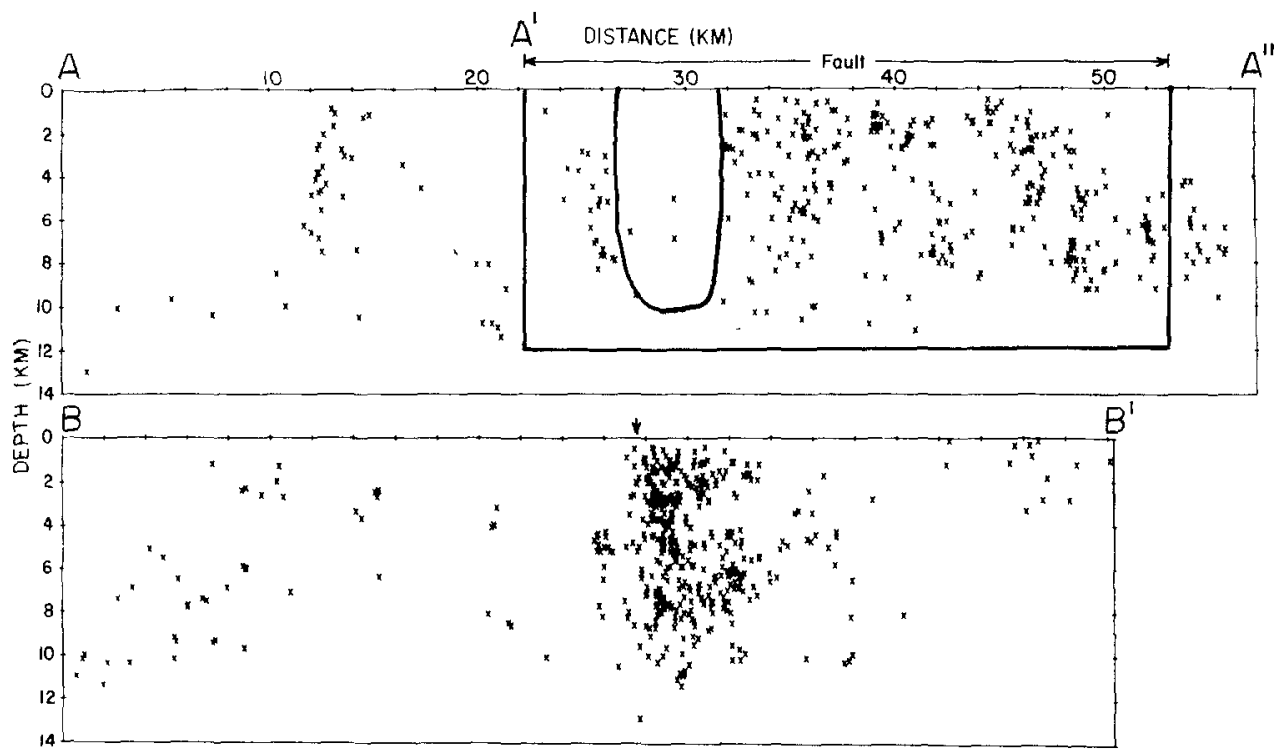

FIG. 18. Plot of aftershock locations with depth on a plane parallel to the surface faultıng and perpendicular to the surface faulting from Hamilton (1972) (A, $\mathrm{A}^{\prime}, \mathrm{A}^{\prime \prime}$ and $\mathrm{B}, \mathrm{B}^{\prime}$ are shown in Figure 1). The arrow in the lower figure denotes the location of the surface faulting. The rectangular box in the upper figure shows the approximate fault area which probably participated in the main shock, and the outlined region under the northern part of the surface break shows the possible location of the asperity on the fault.

there were almost no aftershocks. The size of this gap (which has been outlined in Figure 17) is approximately the same size as that which radiated the high-amplitude body-wave pulses. The surface faulting on the northern segment of the fault breakage did not have any noticeable aftercreep on it while the central and southern parts underwent significant postseismic displacements (Clark, 1972; Burford, 1972; Figure 18). Burford (1972) notes that the basement under the northern part of the surface faulting is covered by a thin layer of sediments, while the basement under 
the central and southern traces lies under several hundred meters to several kilometers of sedimentary rock. He argues that the aftercreep may have been a delayed response of the sediments to the initial coseismic displacement of the basement rock. However, since the aftercreep died away at the same time that the aftershock activity dropped to a very low level (Burford, 1972), it may reflect the existence of postseismic movements in the basement rock.

The high stress-drop beginning of the Borrego Mountain earthquake and the small source area for the initial fault break suggest that this event began with the failure of an asperity. Asperities, or regions of locally high breaking strength on a fault, have been proposed by Kanamori (1977) to explain the multiple rupture of some earthquakes. Rudnicki and Kanamori (1981) have shown that a small, strong asperity on a fault could fail with a very high stress drop and that the crack would then propagate into an area with a much lower breaking strength. The stress drop

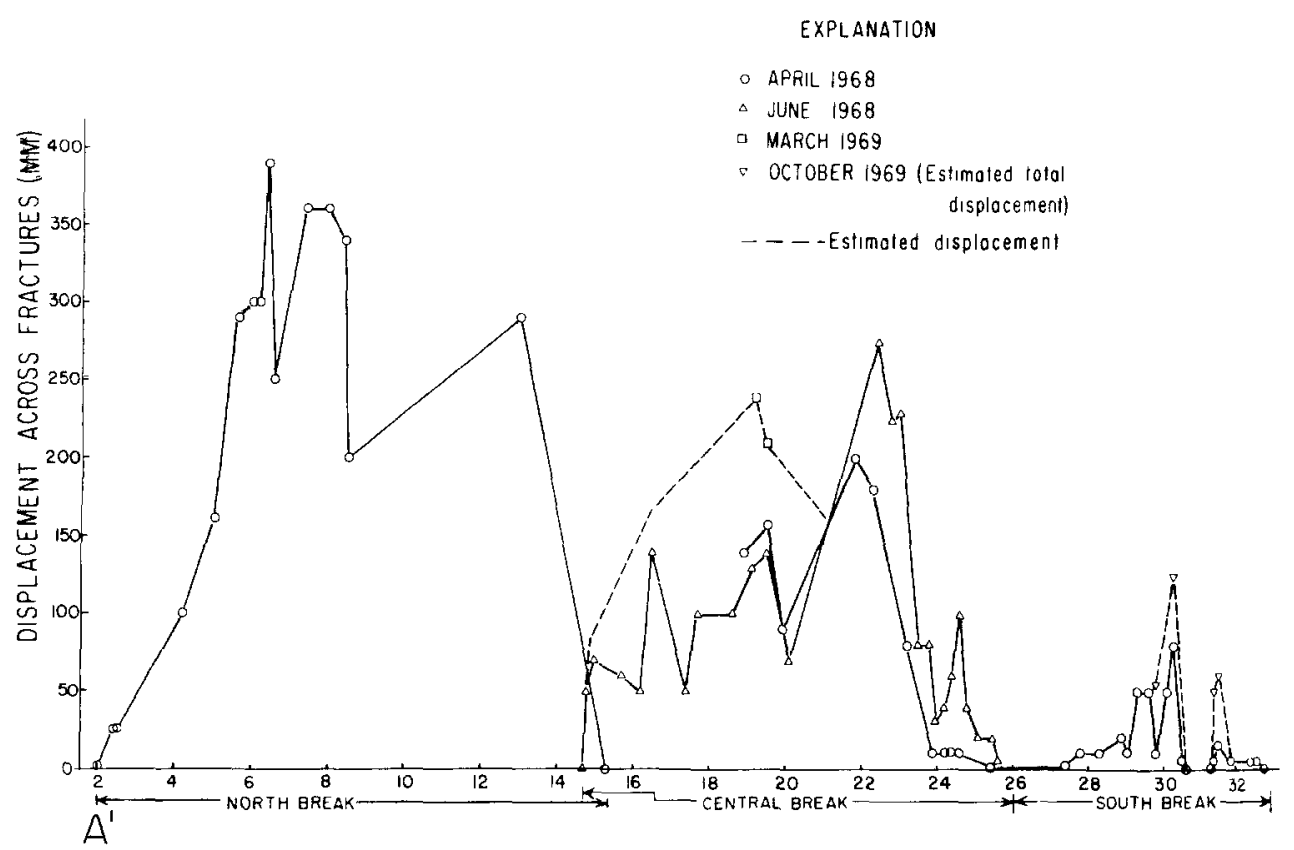

Fig. 19. Graph of the surface faultıng of the Borrego Mountain earthquake from Clark (1972). Point $\mathrm{A}^{\prime}$ is referenced to Figure 1 and the abscissa is scaled in kilometers.

averaged over the entire fault area would be much lower than that of the asperity. The analysis of the Borrego Mountain event indicates that the time history of the stress drop follows that described by Rudnicki and Kanamori (1980) for an asperitycontrolled earthquake. The asperity in the Borrego Mountain fault zone was about $6 \mathrm{~km}$ in diameter and located at the northern end of the fault; the rest of the fault breakage was probably some sort of readjustment to the initial break. The existence of aftercreep on the central and southern parts of the fault zone suggest that not all of this readjustment managed to take place at the time of the main shock. The asperity possibly even had a substantially different strike than did the surface breakage.

The question immediately arises from the above discussion as to whether or not there is any tectonic reason for the existence of an asperity on the northern end of the fault. Since this fault is part of the San Jacinto fault zone which has undergone 
at least $24 \mathrm{~km}$ of displacement (Sharp, 1972), it is possible that the bedrock is different on the two sides of the fault. At the surface, the part of the fault where the maximum coseismic displacement took place is in a zone where Tertiary and Quaternary sedimentary rock on the east abut a part of Borrego Mountain which is made up of crystalline rock on the west (Sharp, 1972). This place is the only location along the 1968 rupture where on the surface there was anything but sedimentary rock in contact across the fault. If there is a contrast of the basement rock across the fault in this area, then the results of this study indicate that this contrast may locally cause the fault zone to have a very high breaking strength. The size and stress drop of the asperity would indicate a fracture strength of about $4 \times 10^{10} \mathrm{erg} /$ $\mathrm{cm}^{2}$, which is even larger than the high value that Aki (1979) calculated for the 1966 Parkfield earthquake. While the surface geology may not be representative of the structure at depth along the fault zone, it can be said that in this case, the location of the asperity correlates with a change in surface geology along the fault zone.

Finally, probably the most important result obtained from this study is the documentation of the role played by asperities in peak intensities. In particular, the high acceleration observed at El Centro appears to be caused by a rather small section of fault which had very little to do with the overall faulting dimension. A similar conclusion can be drawn from a study of the San Fernando strong motions (see Heaton and Helmberger, 1979). Thus, simulation techniques that distribute the high-frequency energy release uniformly along the proposed faulting surface may need some adjustments as in Wiggins et al. (1978) or Hadley and Helmberger (1980). Unfortunately, predicting where asperities will occur for a given fault zone may be very difficult unless they can be recognized by geological features or surmised by seismic data.

\section{CoNCLUSIONS}

The short-period teleseismic $P$ waves from the 1968 Borrego Mountain earthquake have been studied and source models have been found which fit not only those records but the teleseismic long-period body waveforms and the strong-motion $S H$ record at El Centro as well. From the deconvolutions and the forward and inversion modeling of the waveforms, it was found that the source radiation came in two pulses separated by about $2.2 \mathrm{sec}$. The sources for each of these pulses were located at about $8-\mathrm{km}$ depth and had similar focal mechanisms, but the second was only about a third the amplitude of the first. The duration of the time function for the first source is fairly well constrained at about $2.1 \mathrm{sec}$ while there is less resolution on that of the second source. The moment at short periods is 12 to 33 per cent less than that calculated from the long-period data and is 80 to 85 per cent less than that from the surface waves.

There were some problems with the short-period data set. The signal-to-noise ratio is poor on many records and at some stations there is an apparent mismatch of information between the short- and long-period records. There is also some evidence for either laterally varying structure in the source region or for different focal mechanisms at short and long periods. Even so, it was demonstrated that the short-period waveforms contain much detailed information on the source time history of the earthquake and, in particular, on the near-source strong ground motions.

The two sources found in the short-period analysis were determined to have small source areas and large stress drops. However, the average stress drop for the event was much lower, indicating that the earthquake began with the failure of a strong 
asperity at the northern part of the fault. This asperity was located in an area where there was almost no aftershocks, and it lay beneath the place where there is a contrast in rock type across the fault.

\section{ACKNOWLEDGMEN'TS}

Special thanks must be made to several people for their assistance with this study. Gladys Engen ran much of the analysis on the strong-motion data and was responsible for finding the fits to the acceleration record. George Mellman kindly provided his inversion program and made up for the lack of written comments in the program with oral instructions about its inner workings. Dave Boore and Allen Olsen reviewed the manuscript, and their comments prompted some unexpected improvements in the analysis. Joe Galvan and Laszlo Lenches helped prepare the figures. This research was supported by the National Science Foundation under Grant PFR-7921769 and also by the Advanced Research Projects Agency of the Department of Defense and was monttored by the Air Force Office of Scientific Research under Contract F49620-81-C-0008.

\section{REFERENCES}

Aki, K. (1979). Characteristics of barrers on an earthquake fault, J. Geophys. Res. 84, 6140-6148.

Allen, C. R. and J. M. Nordquist (1972). Foreshock, main shock and larger aftershocks of the Borrego Mountain earthquake, U.S. Geol. Surv. Profess. Paper 787, 16-23.

Bache, T. C., D. G Lambert, and T. G. Barker (1980). A source model for the March 28, 1975 Pocatello Valley earthquake from time-domain modeling of telesessmic $P$ waves, Bull. Setsm Soc. Am 70, 405-418.

Burdıck, L. J (1977) Broad-band seismıc studies of body waves, Ph.D Thests, California Institute of Technology, Pasadena.

Burdick, L. J. and G R Mellman (1976). Inversion of the body waves of the Borrego Mountain earthquake to the source mechanism, Bull. Seism. Soc Am 66, 1485-1499.

Burford, R. O. (1972). Continued slp on the Coyote Creek fault after the Borrego Mountain earthquake, U.S Geol. Surv. Profess Paper 787, 105-111.

Cipar, J C. (1981). Broadband tıme domain modeling of earthquakes from Fruili, Italy, Bull Setsm. Soc. Am. 71, 1215-1231.

Clark, M. M. (1972). Surface rupture along the Coyote Creek fault, U.S. Geol Surv Profess Paper 787, $55-86$.

Ehel, J. E., L J. Burdick, and G. S Stewart (1978) Source mechanism of the August 7, 1966 El Golfo earthquake, Bull. Setsm Soc Am. 68, 1281-1292.

Fuchs, K (1966). The transfer function for $P$ waves for a system consisting of a point source in a layered medium, Bull. Setsm. Soc Am. 56, 75-108

Futterman, W. I. (1962). Dispersive body waves, J. Geophys. Res. 67, 5279-5291.

Hadley, D. and D V. Helmberger (1980). Physical basis for the shape of the attenuation relationship, Bull. Setsm Soc Am 70,617-630.

Hamilton, R. M (1970). Time-term analysis of explosion data from the vicinity of the Borrego Mountam, Calıforma, earthquake of 9 April 1968, Bull. Sersm. Soc Am. 60, 367-381.

Hamulton, R M (1972). Aftershocks of the Borrego Mountain earthquake from Aprll 12 to June 12, 1968, U.S Geol. Surv. Profess. Paper 787, 31-54.

Hartzell, S. (1980). Faultıng process of the May 17, 1976 Gazlı, U S.S.R. earthquake, Bull Selsm Soc. Am 70, 1715-1736

Haskell, N A. (1967). Analytic approximation for the elastic radiation from a contained underground explosion, J. Geophys. Res. 72, 2583-2587.

Heaton, T. H. (1977) Generalized ray models of strong ground motion, $P h D$. Thests, California Institute of Technology, Pasadena.

Heaton, T. H. and D. V Helmberger (1977). A study of the strong ground motion of the Borrego Mountain, California, earthquake, Bull. Setsm. Soc. Am. 67, 315-330.

Heaton, T. H. and D. V. Helmberger (1979). Generalized ray models of the San Fernando earthquake, Bull Setsm. Soc Am. 69, 1311-1341

Helmberger, D. V. and S. D. Malone (1975). Modeling local earthquakes as shear dislocations in a layered half space, $J$. Geophys. Res. 80, 4881-4888

Helmberger, D V and L J Burdick (1979) Synthetic seismograms, Ann Rev Earth Planet Scl 7, 417442.

Kanamor1, H (1977). Use of selsmic radiation to infer source parameters, Proceedings of Conference IV. Fault mechanics and its relation to earthquake prediction, U.S. Geol. Surv., Open-File Report 78$380,283-318$ 
Kanamori, H and D. L. Anderson (1975). Theoretıcal basıs of some empirical relations in seismology, Bull Selsm Soc Am 65, 1073-1095.

Langston, C A. (1978). Moments, corner frequencies and the free surface, $J$ Geophys. Res. 83, 34223426 .

Langston, C A and D. V. Helmberger (1975). A procedure for modeling shallow dislocatıon sources, Geophys o 42,117-130.

Mooney, W D. and G A McMechan (1980) Asymptotic ray theory and synthetıc seismograms for laterally varying structures theory and application to the Imperial Valley, California, Bull. Seusm Soc Am 70, 2021-2036

Rudnickı, J. W and H Kanamori (1981) Effects of fault interaction on moment, stress drop and strain energy release, $J$. Geophys. Res 86, 1785-1793

Sharp, R. V. (1972). Tectonic setting of the Salton trough, U.S. Geol. Surv Profess. Paper 787, 3-15.

U.S. Coast and Geodetic Survey, Seismological Field Survey and Californı Instrtute of Technology, Earthquake Engineering Research Laboratory (1968). Strong motion instrumental data on the Borrego Mountain earthquake of 9 April, 1968, no 119.

Wiggins, R. A., G. A Frazier, J Sweet, and R. Apsel (1978). Modeling strong motions from major earthquakes, Proceedings of the Second International Conference on Microzonation, NSF, vol. II, 693-699.

SEISMOLOGICAL LaBoratory

California Institute of Technology

Pasadena, California 91125

Contribution No. 3523

Manuscript recelved 13 November 1980 